\title{
Parent-Child Relationship and the Child's Inner Feelings Regarding Dependency - Japan
}

\author{
Maha El Helbawey, Ph.D. \\ Psychology Department \\ Faculty of Arts, Benha University*
}

\begin{abstract}
A physiological boundary relationship between Japanese mothers and children encountered with the socio-cultural system has rooted a feeling of dependency and reliance on the society,which deny self-identity and independency. This system raises hate between the individual and the family and society. The current study investigates the parents and children's attitude toward treatment, focusing on the children's attitude toward treating their parents and the children's inner feelings toward family. Fifty-nine Japanese elementary school students have been given the Father/Mother-Child Relationship Inventory $(\mathrm{FMCl})$ and the Kinetic Family Drawing Test (K.F.D). Children have shown a dependent common attitude; and aggressive inner feelings toward parents. Children have had such double-injured, tendency of dependency and lack of family warm relations. Hence, those children who have shown rebellious, strange and refusal attitudes toward their parents are considered to be normally reacting in a healthy way.

Key Words: FMCl (Father/Mother-Child Relationship Inventory), K.F.D. (Kinetic Family Drawing Test), Dependency

\section{Introduction}

Love in the east is all-embracing. It is open to all sides; one can enter from any direction. The mother enfolds everything in an unconditional love. There is no question of right and wrong, everything is accepted without difficulties, Suzuki Daisetsu (as cited in Doi, 1977). The parent-child relationship is a combination of behaviors, feelings, perceptions, thoughts and expectations that are exclusive to a particular parent and a particular child. The relationship involves the full extent of a child's development (Krapp,

* I would like to express my deep gratitude to Professor Hisaya Nonoyama, Sociology Department, and Professor Shigeki Mori, Psychology Department, Konan University, Japan, for their collaborative support . I would like to thank Miss Midori Nishiyama, Mrs. Itsuko Domen, the staff and the students of Motoyama DaiNi Elementary School for their cooperation and their valuable drawings that enriched my research.

This research was supported in part by a grant from the ministry of higher education in Egypt as a post doctoral fellowship from Nov. 2008: Aug. 2009 in Konan University, Kobe, Japan. The study had been presented in the Asian Conference on psychology and the behavioral sciences (ACP) at 2011 in Osaka, Japan. 
Wilson and Cengage, 2005). Theories perspectives are different, they almost focus on the influence of the socio-cultural context, early childhood and unconscious, individual inbuilt potentials, environmental events and the interpersonal dynamics in the family system. Although parent-child relationship and dependency seem to be overlapping concepts, they stem from two different theories; psychoanalytic theories of object relations and social learning theories of dependency and attachment (Ainsworth, 1969). Socio- Cultural and Family Systems Perspective believe the influences of culture on the individual's behaviors and representations; also both parent - child behaviors are in reciprocal causality (Lollis and Kucynski, 1997). Harry stack Sullivan, interpersonal relationships perspective, coined the term "Personifications" to refer the embody one's assumptions, schemata, internalized representations of others and reflected appraisals of the self (Brinich and Shelley, 2002, p.65). Object relation's theory indicate the infant - caregiver relationship that internalized images of one's parents that reshape later experiences. (St. Clair, Michael, 2000). According to the social learning theory Bondura stressed the importance of observational learning and suggested how individual's environment, cognition, and behavior all integrate and ultimately determine how the individual functions. The Key tenet's of social learning theory: learning is behavioral, cognitive process take place in a social work; observing behavior and the consequences of the behavior; Observational learning model; reinforcement, and reciprocal determinism, Grusec (1992).

A social model (Parent, Sibling, friend or teacher, Particularly in childhood is a model is some one of authority, Asocial model is very important to facilitate cognitive process behavior to encode and store what they observe and imitate it later; desirable or undesirable behaviors.

The Attachment theory indicates that. The attachment models of young children are typically assessed in relation to particular figures, such as parents or other caregivers. (Kerns KA 2008). In the attachment theory, individual's differences in the relationships reflect the history of care, as infants begin to predict the behavior of caregivers through repeated interactions... the focus is the organization (pattern) rather than quantity of attachment behaviors. (Weinfield, et al, 2008).

In Japan, the social system and cultural values are very strong, strict and highly recommended to follow, which strongly affects the family structure, roles and relationships; At the same time, Japanese people have the tendency to idealize the parent-child relationship and use it as a reference in other relationships. Today, the family relationship has changed due to more life stresses and money seeking; parents have become less close and less attached to their children. At the same time, children are still asked to follow 
the strict system and depend on their parents first and then on the group. A close physical and psychological attachment between Japanese mothers and their infants has been emphasized as a socio-cultural recommendation in order to socialize the children into social and group dependency patterns. Interdependency can be found and amae's mentality (Doi, 1973, 77), the unique Japanese concept of dependency (Behrens, 2004), the desire to be passively loved and tendency to depend on mother, parents, principles and organization.

* Amae is a Japanese term that refers to the feelings that all normal infants at the breast harbor toward the mother dependency, a desire to be passively loved, unwillingness to be separated from the warm mother-child circle and cast into a world of objective "reality". In Japanese. These feelings are somehow prolonged into and diffused throughout his adult life. (John Bester as cited in Doi, 2008, P.7).

Doi (1977) argued that amae is distinctive to the production and reproduction of Japanese culture, and is what makes Japanese child rearing peculiarly different from that of other cultures and American culture per se. The Japanese parent-child relationship is physiologically bounded, the mother thinks that the child is an extension of her own, needing no verbal communication, which may indicate controlling the verbal system as a cultural demand in order to maintain a certain model of what a child's development should be like. Doi describes the intimate parent-child relationship that encourages the offspring's extensive reliance on the mother, who in turn rewards and accepts dependent behavior as an indication of her enhanced affection (Shwalb and Shwalb, 1996). Rothbaum et al (2007) found that Japanese mothers link security with accommodative behaviors in mildly stressful situations and attribute the child's inappropriate behavior to security and interdependence needs more than US mothers do. Obviously, it is a cultural value and an influence of amae's mentality. The Japanese person who depends on the group is not allowed to be independent, which leads him to psychosocial conflicts (Doi, 1977, 86-135).

The unconditioned mother's love and the spirit of non-discrimination of motherchild has been a part of the Japanese makeup since ancient times (Doi, 2008, P.78). This close relationship between the mother and the child encountered with the socio-cultural system has rooted the tendency toward dependency.

\section{The problem:}

In Japan mothers, parents, groups, organizations, and society-dependent relationships deny self-identity and independency, which raises the conflict and roots 
hatred between the individual and the group (family - society). Family relationships today have changed (life stresses, seeking money) and parents are considered to be absent at the same time, children are still asked to follow the system and depend on parents.

It's important to identify, according to the Japanese children's status, both parents and children (Boys, and Girls) attitudes toward relationship, and try to investigate the deep and inner child's feeling toward parents. Thus, the aim of the current study is to:

1-Identify the parents and children's attitude toward relationship.

2-Illustrate/Investigate the deep children's feelings toward their parents regarding dependency that is recommended by the Japanese strict system and influenced by Amea's Mentality.

\section{Questions of the Study}

The present study has two procedural stages: the first stage aims to identify the attitudes of parent-child relationship in comparison to the child attitudes. This purpose is accomplished through the child's self-report responding on the two facets of Father Mother and Child Relationship Inventory (FMCl); the daily life scenes and studying circumstances scenes. The specific questions of this stage are:

1. What is the parental attitude toward the child? What are the attitudes perceived by the child toward parents?

2. Are there gender differences in their perception of parent-child relationship or parental attitudes?

The second stage explores the inner feelings of the students by way of the Kinetic Family Drawing technique; this projective technique allows the child to experience free association of his feelings toward his family without social or psychological constraints. The main question that the researcher tries to investigate is: What are the child's inner feelings that are related to (dependent/ independent) child-parent relationship?

The Japanese indigenous concept of amae indicates a specific quality of relationships, namely interdependence (Carolus Vereijken, 1997) that is not captured by the western concepts of attachment and dependency. The study of Carolus Vereijken (1997), Eight Japanese behavioral scientists were asked to describe Amae using the attachment Q-sort. This description was compared with descriptions of dependency and attachment security as provided by western experts. Carolus found that Amae and dependency are highly similar and both concepts are unrelated to attachment security, and the Japanese mothers consider attachment security gathering the most desirable features of the three concepts (attachment, dependency and amae), whereas amae itself is considered the least desirable. 
The research literature on attachment in infants and preschool-aged children is extensive, but it is limited in late childhood and adolescence (Scott, Briskman, Woolgar, Humayun, and O'Connor, 2011). In case of Japanese culture, the child dependency as amae innate desire research is obviously rare. Some studies concluded that psychological dependency predicts dysfunctional family systems, and is related to a distant relationship with fathers during development, but is marginally related to perceptions of increased parental attention and overindulgence. Besides, they found dependency to be related to favorable representation of parents for friendly and submissive, but not hostile situations (Marchiori, Loschi, Marconi, Mioni and Pavan, 1999 Using the dependence self-rating scale (DSRS) in 33 alcoholic and 34 non-alcoholic inpatients; Rosenfarb, Becker, Khan, and Mintz, 1994 The sample was 132 female bipolar, non bipolar depressed and non psychiatric control female Ss, age 18 year \& older ; Mongrain, 1998 ). Hence, dependency as a parent-child relationship representation has an impact on late adolescent development and it may also play a role in the origin of some adolescent and youth problems. On the other side a sample of fifth, eighth-, and eleventh- graders $(\mathrm{N}=516)$, in the study of Waller and rose, (2010) they use disclosure questionnaire, network of relationships inventory, family adaptation and cohesion scales IV, and youth self -report, and found that the positive quality of mother-adolescent relationship is found to be related to verbal communication it reflects adolescent independency.

Abnormal parent-child relationship is a serious risk factor in the development of child and has a great impact on child behavior such as sleep organization (Vaughn, ElSheikh, Shin, Elmore-Staton, Krzysik and Monteiro, 2011); developmental and psychosocial problems (Hakvoort, Bos, Van Balen, Hermanns, and Jo, 2010; the sample was 88 in the middle childhood, using Marital satisfaction scale, strengths, and difficulties questionnaire, Akca et al, 2011 the sample was 457 children 1 : 59 months using the Parent - In fact Relationship Global Assessment Scale (PIRGAS), Ankara Developmental Screening Inventory and Bayley Scales of Infant Development Screening Inventory); children's maladaptive responses to stressors (Lucas-Thompson, Goldberg, 2011); conduct problems (Raya, Pino, and Herruzo, 2011; Raudino, Woodward, Fergusson, Horwood, 2011); and depressive symptoms and depressive episodes in children and adolescents, participants were 325 children and adolescents bereaved of a parent compared to 129 non-breaved community controls and 110 non-bereaved depressed controls participants and their parents were interviewed regarding the child's depressive symptoms using psychiatric diagnostic interview, children's depression inventory, children's depression rating scale, diagnostic interview for children and adolescents and Hamilton 
rating scale for depression (Gray et al, 2011). Page, Fedele, Pai, Anderson, WolfeChristensen, Ryan and Mullins (2011) conclude that maternal uncertainty is directly related to child depressive symptoms. On the other hand, Malmberg and Flouri (2011) found that mother-child relationship and maternal depressed mood have larger effects on children's problem behavior than father-child relationship and paternal depressed mood.

Some studies have focused on the mother's attitude and its impact on the child dependency. Bousha et al (1984) investigated three groups of mothers with a known history of child abuse and neglect, The children were observed in their homes using coding system of 11 major interaction patterns ; The results conclude that dysfunctional subjects showed significantly less positive behaviors than did the controls on verbal, nonverbal and physical aggression; the neglectful mothers had the lowest overall rates of interaction. The maltreated children also exhibited fewer positive behaviors and more aggressive behaviors. These results were consistent with the notion of Wolfe and Mclsaac (2011) who claimed that child emotional maltreatment could be more extreme and potentially more harmful behaviors than poor parenting. This agrees as well with Makoto (2009), who found that mothers of children who are more dependent in kindergarten as well as in family are more rejecting and negative than mothers of children who are less dependent in kindergarten. These findings simply suggest a relationship between the low quality or rather negative relationships and child dependency, which may also reflect poorer childhood well being.

A mutual influences between individuals with a relationship and mutual influences among relationship that had included by the family system theory, Hinde (1989) and a cycles of reciprocal, causality in Pareant and child relationship (Lollis and Kuczynsk, 1997).

Earlier reviews (Fraser, 1996) on the development of aggressive behavior in childhood and early adolescence suggested that family processes and early childhood appear to tip developmental trajectories toward social rejection at school and use of aggression to achieve social goals in interpersonal relationships. Besides, Williams, Conger and Blozis (2007) used the Latent growth Curve modeling employed data from a Longitudinal study of 451 Sibling families and suggested that individual change in interpersonal aggression during adolescence can be predicted by the gender and aggression of one's sibling and rates of parental hostility predict levels of interpersonal aggression. Parents who present high support for adolescents suffering from internalizing difficulties during childhood are associated positively with social anxiety, while low support from parents mediates the relationship between angry rejection sensitivity and depressive symptoms. The study of Richaud de Minzi, 2006 the sample was 8-12 years 1,019 483B, 
536 G used the Argentine scale; McDonald, Bowker, Rubin, Laursen and Duchene, 2010). These results are confirmed by Branje, Hale Frijns and Meeus (2010) The sample was 1313 Dutch adolescents 12-16, using the Latent Class Growth Analysis, children depressive inventory and the inventory of parent and peer attachment; they found that relationship quality to mothers predicted depressive symptoms for boys and girls, but relationship quality to fathers predicted depressive symptoms only for boys.

\section{Dependency:}

A distinction between attachment "The relationship between infant and caregiver" and Dependency "The reliance of the child on Adults for nurturance, attention, or assistance" has been studied through the early social development. Sroufe and et.al, (1983) assessing 40 children (12-18) months using teacher ratings, rankings and $Q$ sorts and suggested that dependency has its roots in the quality of early infant-caregiver relationship, and Individuals differ in their infant-caregiver attachment. The secure attachment in infancy, as it is an effective dependency, provides the conditions for emerging self-confidence and autonomous functioning (Sroufe \& et,al , 1983). Both dependency and attachment refer to a class of behaviors that maintain contact and elicits reciprocal attention and nurturing behavior from another one or more individuals, (Maccoby \& Masters, 1970).

In the Diagnostic and statistical Manual of Mental disorders (DSM-IV) Depending personality disorder (DPD) is a personality disorder that is characterized by a pervasive psychological dependency on other people with chronic condition in which people depend on others to meet their emotional and physical needs with a minority achieving normal levels of independency... DPD include fear of expressing disagreement because of possible loss of support... and the difference between "a dependent personality" and "a dependent personality disorder" is somewhat subjective, which makes a diagnosis sensitive to cultural influences, such as gender role expectations. www.wikipedia.org.

In DPD dependency focuses on the close personal relationship with a person (ex, parent) and the individual. Obedience to the other's wishes is common (comer, 2010). Bienenfeld pointed that there are no studies of genetics or of biological traits for dependency have been conducted, and mentioned the Psychodynamic causes of an insecure form of attachment to others, which may be the result of clinging parental behavior. (Bienenfeld, 2008); That may agree with Sroufe that the quality of infant - Caregiver attachment influences later dependency. It is, that. Amea and the unique status of the Japanese culture (unique mother-child relationship, group, and 
society dependency). The word Amae is a Japanese word coined from the verb amearu by Takeo Doi to serve the behavior of a person attempting to induce an authority figure, such as parent, teacher, etc. to take care of him. In the western world seeking to stop this kind of dependency has been suggested, while it continues into adulthood in close relationships in Japan. (Herman \& Takako, 2000). Doi states that Amea is not just a Japanese phenomenon, but the Japanese are the only people who have an extensive vocabulary describing it. (Doi, 1981)

\section{Method}

The method used in this study is a combination between two approaches: the first approach is a descriptive and quantitative method to identify the distribution of parent-child relationship attitudes, and then determine the percentage of the dependency style among the target sample. The second approach is an in-depth analysis of children's responses to a projective test (KFD). It is expected that the data obtained from both methods cross-validate each other. Subsequently, the child can reveal his dependency relations and his inner feelings toward his/her parents.

\section{Participants}

Letters of consent were sent to the parents of $6^{\text {th }}$ graders in a Japanese elementary public school (Motoyama Dai Ni, Kobe, JAPAN), for allowing children to take part in the study "as an essential step for measuring attitudes in Japan". 60 parents representing 60 students agreed to participate in the research work. 59 Japanese sixth graders at an elementary school aged 11-12 and only one boy aged 10 were included in the research work. The sample consists of 31 girls $(11.73+0.25)$ and 28 boys $(11.68+0.47)$ without gender differences in age $(t=-$ 0.556). One student did not respond to the questionnaire $\mathrm{FMCl}$, and only 30 students accepted the K.F.D. Test because it was difficult to assign all students (60 students) to draw individually or separately during school time. Thus, 59 students answered the questionnaire and 30 students responded to the drawing test.

\section{Tools}

The Father/Mother-Child Relationship Inventory (FMCl) ${ }^{*}$ is a child selfreport measure of relationships with the father and the mother at both daily life scenes and studying circumstances scenes. At each scene, the parents' attitude to

\footnotetext{
* FMCl sheets have applied and corrected by Miss Midori Nishiyama, Master degree of Psychology at Konan university, Kobe, Japan.
} 
the child has two traits: refusal-acceptance and control-understanding. The child's attitude to their parents has two traits: dependency-independency and resistancereliance, with sub-classifications for attitudes (Kotaro, 1998). Hiroyuki Tahara, Minoru Okita, Toshiya Tsurusaki, Shigeru Inokuchi and Toshio Higashi (1997) examined the reliability and validity of the Japanese version of $\mathrm{FMCl}$ on 244 primary school children. Cronbach's $\alpha$ coefficient for the scale was 0.94 and 0.91 indicating satisfactory reliability, and no difference was observed between male and female for the FMCl. Criterion-related validity was supported by a significant correlation of the Self-Esteem Inventory and the $\mathrm{FMCl}(\mathrm{r}=0.49, \mathrm{p}<0.01)$.

The Kinetic Family Drawings (KFD) is a projective drawing test which allows the child in an easy way to express his/her feelings and the dynamic family relationship, emotions, aggression, which cannot be expressed through verbal talk and which are easy to conduct and yet exceed linguistic and cultural limits (Burns and Koufman, 1970, 1972)

While Kinetic Family Drawings is a popular assessment tool for clinicians, research on developmental issues and how children draw their families is rare. KFD is a common tool for cultural family research that gives particular advantages (Anderson, 2004). Drawing, as a means of communication, is universal, able to transcend boundaries of nation and culture, carrying meanings that, while specific to one culture, may be understood by members of another. It can convey complex family systems in an at-a-glance presentation (Bowers, 2002). The KFD ability to discriminate families with differing styles and to assess family dynamics is affirmed by Schwartz, (1981). Stawar and Stawar (1989) found that Kinetic Family Drawings indicators of depressive, anxiety, behavioral and thought disorders and diagnostic category are as valid as those of the Minnesota Multiphasic Personality Inventory (MMPI). The KFD provides researchers and clinicians with unique information about the inner, suppressive, deep feelings of subjects regardless of age, gender, education, ethnicity or culture.

The evidence that was gathered in this context revealed that the KFD is effective for reflecting the dysfunctional father-daughter relationship, specifically dependence in relationships, which is a major characteristics of eating disordered women (Buogla, 1995); the way siblings perceive themselves and their family interpersonal relationships (Anderson, 2004); possible developmental age differences of personal and family dynamics (Lieberman, 1992; Anderson, 2004); children's perception about the importance of the mother as the primary care giver 
and organizer of the family (Lieberman, 1992); and children's emotional conflicts and psychodynamic defenses (Monahan, 1985). However, there are some questions about the validity of the scoring system and reliability of the KFD's utility in enhancing communication and building rapport with children (Monahan, 1985; Chamberlain, 2002). The use of KFD as a projective test is still a successful measurement of children's inner feelings, specifically dependence/independence relationship style related feelings (Bugola, 1995; Monahan, 1985; Lieberman, 1992).

\section{Results}

Table (1)

Parent's attitude toward the child (Daily life scenes)

\begin{tabular}{|l|l|l|l|l|}
\hline $\mathbf{P}$ & $\mathbf{Z}$ & \multicolumn{1}{c|}{ ws $(\mathbf{n}=\mathbf{2 8})$} & \multicolumn{2}{c|}{ rls $(\mathbf{n}=\mathbf{3 1})$} \\
\hline 0.23 & 1.216 & $(10.7 \%)$ & $(22.6 \%)$ & Acceptance/ receptive \\
\hline 0.12 & 1.564 & $7(25 \%)$ & $\beta(9.7 \%)$ & Blind love \\
\hline 0.385 & 0.875 & $7(25 \%)$ & $(35.5 \%)$ & Ideal \\
\hline 0.05 & 1.968 & $-(0 \%)$ & $4(12.9)$ & Average \\
\hline 0.24 & 1.192 & $7(25 \%)$ & $4(12.9)$ & Toritative /despotic control \\
\hline 0.256 & 1.146 & $(10.7 \%)$ & $(3.2 \%)$ & Neglect/ refusal \\
\hline 0.933 & 0.085 & $1(3.6 \%)$ & $(3.2 \%)$ & Understanding \\
\hline
\end{tabular}

Frequencies, percentages and the difference between two proportions $z$ test are shown in Table 1. The girls and boys daily life scenes perceptions of their parents' attitudes were almost not significantly different, but $12.9 \%$ of the girls reported average parental attitudes while zero percent of the boys reported that. Due to daily life scenes, the parental common attitude toward children was almost acceptance attitude $(67.7 \%$ of Girls \& $60.7 \%$ of Boys), if we consider that blind love and ideal attitude are an acceptance attitude. However, we notice that boys tend to perceive their parents as authoritative/despotic and neglectful compared to girls, while girls tend to perceive their parents as idealistic and accepted.

Table (2)

Child Perceptions of their Parent-Child Relationship Daily Life Scenes

\begin{tabular}{|l|ll|l|c|}
\hline \multicolumn{1}{|c|}{$\mathbf{P}$} & $\mathbf{Z}$ & ys $(\mathbf{n}=\mathbf{2 8})$ & \multicolumn{2}{c|}{ rls $(\mathbf{n}=\mathbf{3 1})$} \\
\hline 0.812 & 0.239 & $\rho(35.7 \%)$ & $(38.71 \%)$ & $\begin{array}{c}\text { ndent - childish pampered } \\
- \text { Reliance }\end{array}$ \\
\hline 0.213 & 1.258 & $5(18 \%)$ & $(32.3 \%)$ & Ideal \\
\hline 0.546 & 0.607 & $(10.7 \%)$ & $(16.12 \%)$ & Average \\
\hline
\end{tabular}




\begin{tabular}{|l|l|l|l|l|}
\hline 0.100 & 1.669 & $(21.4 \%)$ & $(6.5 \%)$ & $\begin{array}{l}\text { Resistance } \\
\text { Rebellious }\end{array}$ \\
\hline 0.50 & 0.677 & $2(7.1 \%)$ & $(3.23 \%)$ & Independent \\
\hline 0.50 & 0.677 & $(7.1 \%)$ & $(3.23 \%)$ & Estrangement \\
\hline
\end{tabular}

As shown in Table 2 shows that $38.7 \%$ of girls and $35.7 \%$ of boys report that their relationship pattern is dependent, childish, pampered (Reliance). Approximately, $21 \%$ of the boys tend to perceive themselves as rebellious and resistant compared to $6.5 \%$ of the girls, while $32.3 \%$ of the girls tend to perceive the relationship as ideal compared to only $18 \%$ of the boys.

The hierarchical order that represents the potential relationship between parent and child (Daily Life Scenes)

\begin{tabular}{|l|l|l|l|l|}
\hline & \\
\hline
\end{tabular}


fnes that are self-reported by Japanese es that are self-reported by Japanese girls
boys

Table ( 3 )

Parent's Attitude toward the Child (Studying Circumstances Scenes)

\begin{tabular}{|l|l|l|l|l|}
\hline \multicolumn{1}{|c|}{$\mathbf{P}$} & $\mathbf{z}$ & oys $(\mathbf{n}=\mathbf{2 8})$ & \multicolumn{1}{c|}{ irls (n=31) } \\
\hline 0.875 & 0.157 & $4(14.3 \%)$ & $(12.9 \%)$ & ceptance/ receptive \\
\hline .464 & .737 & $2(7.1 \%)$ & $4(12.9 \%)$ & Blind love \\
\hline 0.049 & 2.007 & $5(17.9 \%)$ & $13(42 \%)$ & Ideal \\
\hline 0.915 & 0.107 & $2(7.1 \%)$ & $2(6.4 \%)$ & Average \\
\hline 0.081 & 1.775 & $(32.2 \%$ & $4(13 \%)$ & $\begin{array}{c}\text { thoritative /despotic } \\
\text { control }\end{array}$ \\
\hline 0.55 & 0.593 & $\beta(10.7 \%)$ & $2(6.4 \%)$ & Neglect/ refusal \\
\hline 0.55 & 0.593 & $(10.7 \%)$ & $2(6.4 \%)$ & Understanding \\
\hline
\end{tabular}

As shown in Table 3 shows that $42 \%$ of the girls and $17.9 \%$ of the boys tend to perceive parent attitude toward studying circumstances as idealistic. Due to studying circumstances, the parental common attitude toward children was almost acceptance attitude (67.7\% of the Girls and $60.7 \%$ of the Boys), if we consider that blind love, ideal and acceptance attitudes constitute acceptance category. Yet, we notice that $42.9 \%$ of the boys tend to perceive their parents as authoritative/despotic and neglectful compared to $19.4 \%$ of the girls.

Table (4)

Child Perceptions of their Parent-Child Relationship (Studying Circumstances

Scenes)

\begin{tabular}{|l|l|l|l|l|}
\hline P & $\mathbf{z}$ & oys $(\mathbf{n}=\mathbf{2 8})$ & \multicolumn{2}{|c|}{ irls (n=31) } \\
\hline .394 & 0.859 & $5(53.5 \%)$ & $0(64.5 \%)$ & $\begin{array}{l}\text { ppendent - childish } \\
\text { mpered - Reliance }\end{array}$ \\
\hline 0.291 & 1.066 & $(3.6 \%)$ & $(0 \%)$ & Ideal \\
\hline 0.464 & 0.737 & $(7.1 \%)$ & $4(12.9 \%)$ & Average \\
\hline 0.501 & 0.677 & $(7.1 \%)$ & $(3.23 \%)$ & $\begin{array}{l}\text { Resistance } \\
\text { Rebellious }\end{array}$ \\
\hline 0.899 & 0.127 & $(10.7 \%)$ & $3(9.7 \%)$ & Independent \\
\hline 0.357 & 0.928 & $5(18 \%)$ & $3(9.7 \%)$ & Estrangement \\
\hline
\end{tabular}


As shown in Table 4 shows that $64.5 \%$ of the girls and $53.5 \% \%$ of the boys report that their relationship pattern is Dependent, childish -pampered (Reliance). Approximately, $7 \%$ of the boys tend to perceive themselves as rebellious and resistant compared to $3 \%$ of the girls, while $13 \%$ of the girls tend to perceive the relationship as ideal compared to only $7 \%$ of the boys.

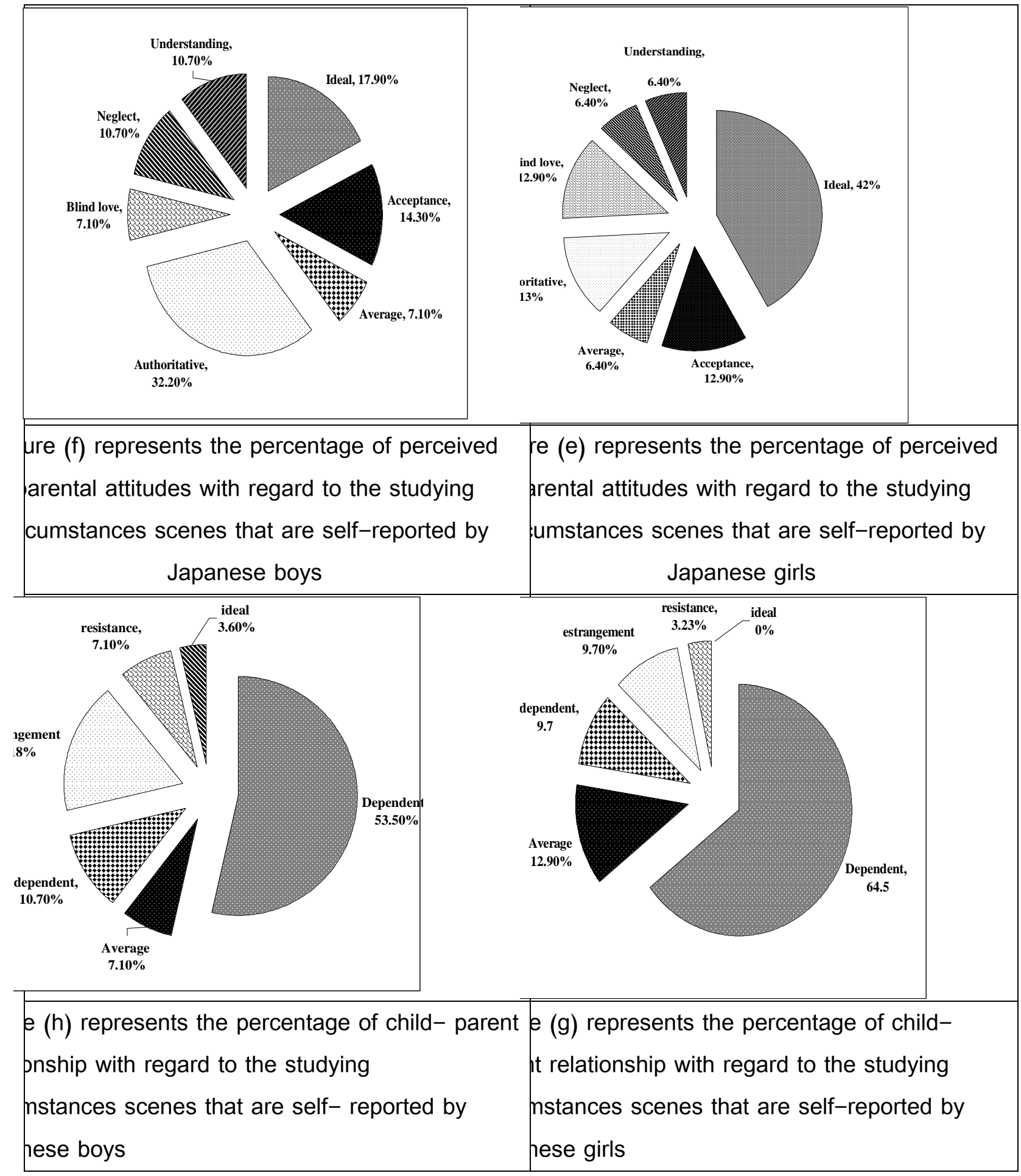

Analysis of Students' Drawings: 


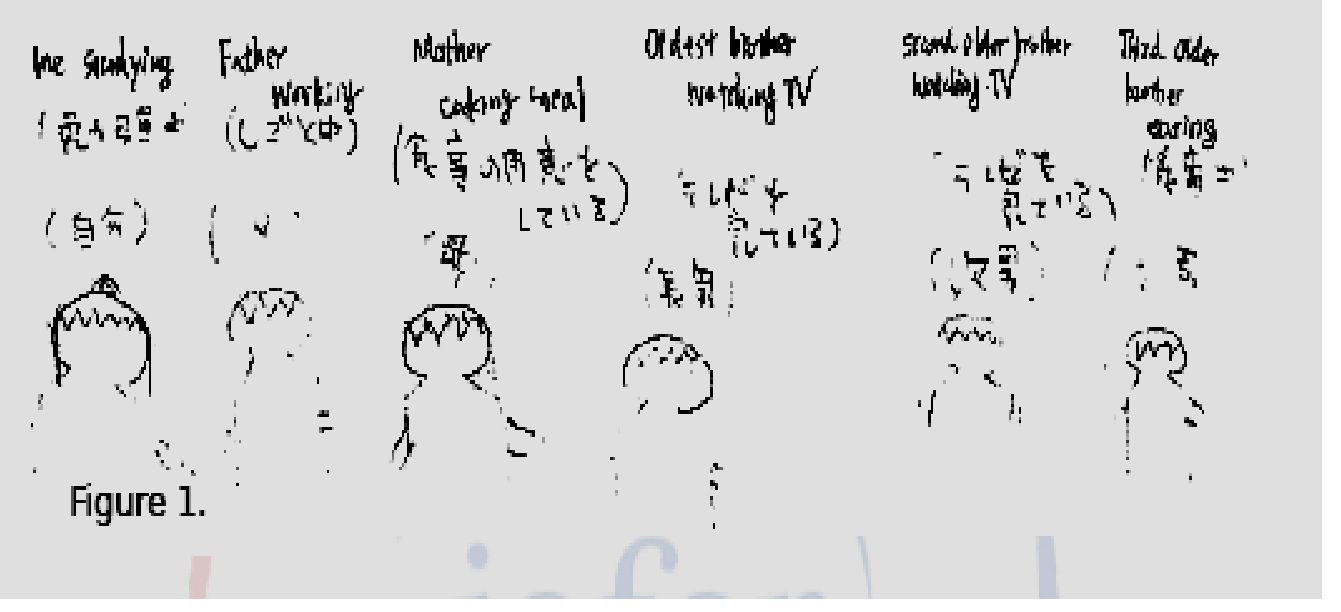

FIGURE 1

As shown in Figure 1. This figure shows a girl who has a rebellious attitude toward parents in daily life and an independent attitude in studying circumstances. She has shown a strong indication of aggressive inner feeling toward parents, family, and self (distorted human body image), non-human family communication and feelings, and refusing the family situations (omission of human facial features, hands, legs) where human beings can communicate, lose of independency (omission of foots), identification with mother (long here) and father attachment (father close to her). No motor action can be seen that may indicate such a depressive sign.

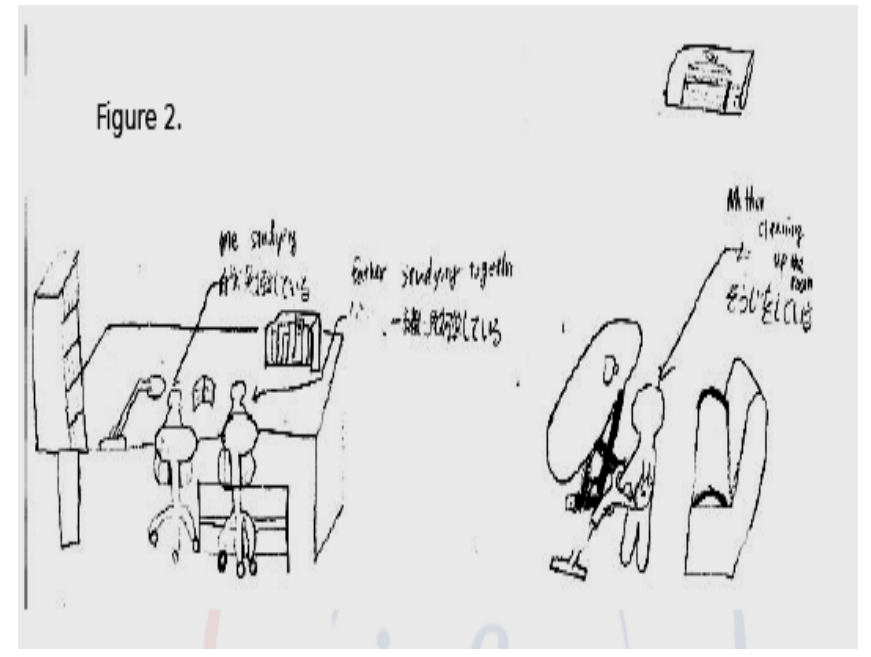

FIGURE 2

As shown in Figure 2. This figure shows a girl who has a dependent attitude toward parents in both daily life and studying circumstances; she has shown an aggressive inner feeling toward parents (strong indication of a non-human body image of parents with no human feelings; they seem to be like machines), distorted 
body image, and refusing family communication (omission of the human facial features), lose of independency (omission of foots), Identification and attachment with father can be seen through (sitting beside him and studying together); maternal love deprivation can be seen through (long distance between mother and her); the mother is supposed to be ironing "giving love", but she is not; the girl has drawn a "shaded X" under the ironing table, signifying "No love, No warmness"; the mother is vacuuming and there is a lack of motor action.

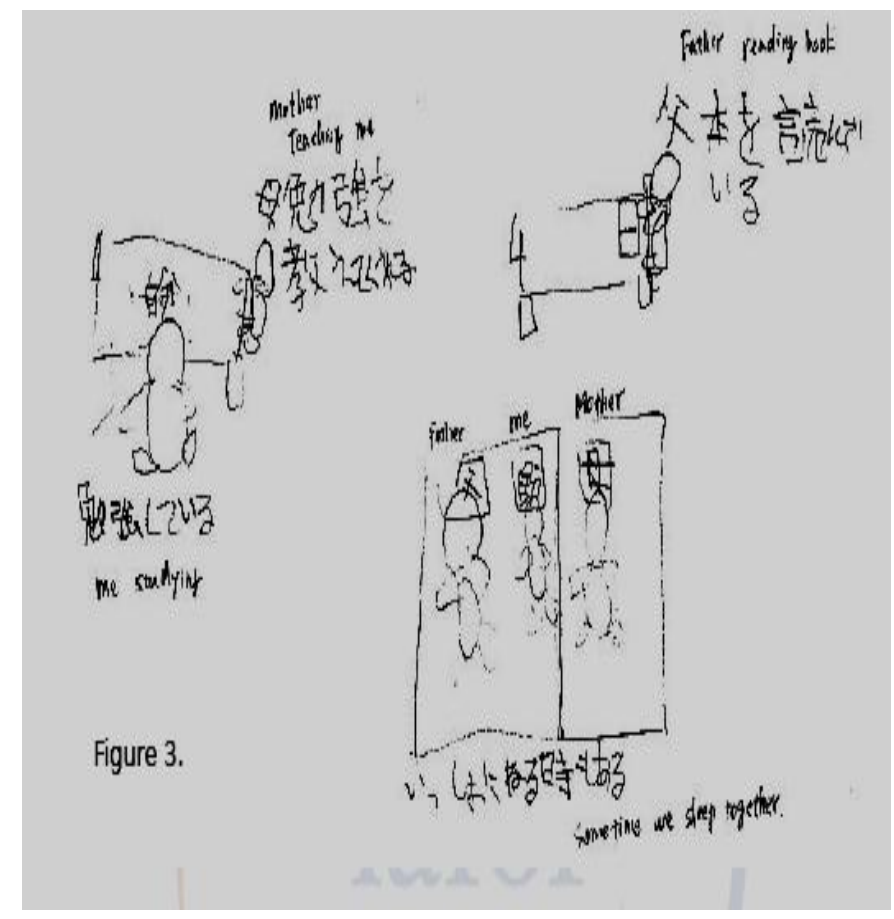

FIGURE 3

As shown in Figure 3. This figure shows a boy who has a dependent attitude toward parents in both daily life and studying circumstances. Omission of the human facial features and body parts (distortion) may indicate to such an aggressive feeling and refusal of family communication, lose of independency (omission of foots), Maternal attachment and Oedipus situation (studying with mother and sleeping between parents) are clear; however, father attachment can be seen (a compartment holding him and his father only) that may indicate such hesitating of the process of identification; drawing tiny persons may indicate such a feeling of inadequacy. 


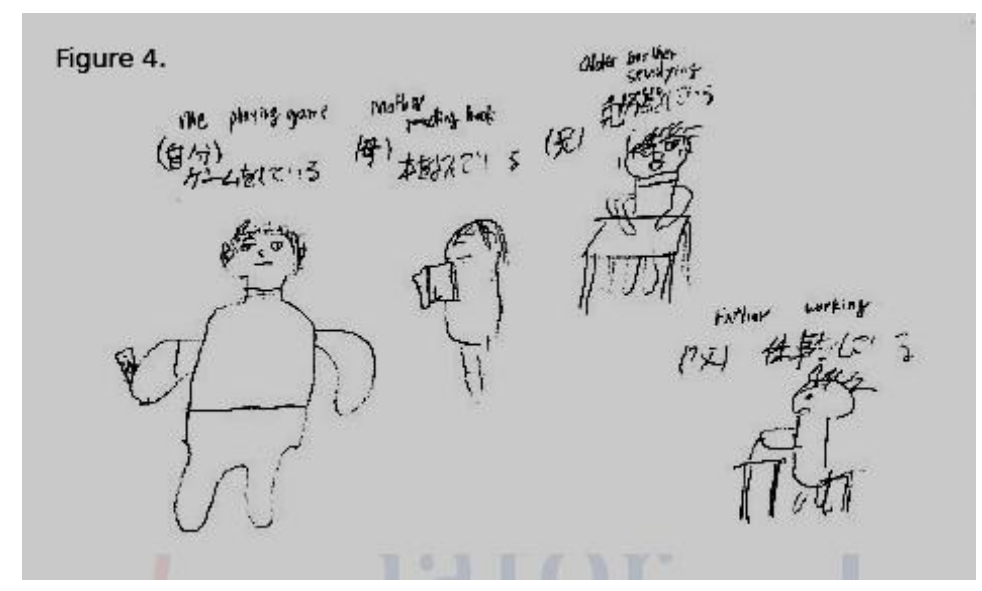

FIGURE 4

As shown in Figure 4. This figure shows a boy who has a dependent attitude toward parents in daily life and a rebellious one in studying circumstances. He has shown aggressive inner feelings toward parents, especially the father (distorted and tiny persons drawn to represent the figures of parents and the older brother; long distance between the boy and his father); lack of human family communication; childish image of parents, compared to self-image; lose of independency (omission of foots), and refusal of the family situation, while parents are looking in his way/direction but he is neglecting them with a narcissistic attitude .

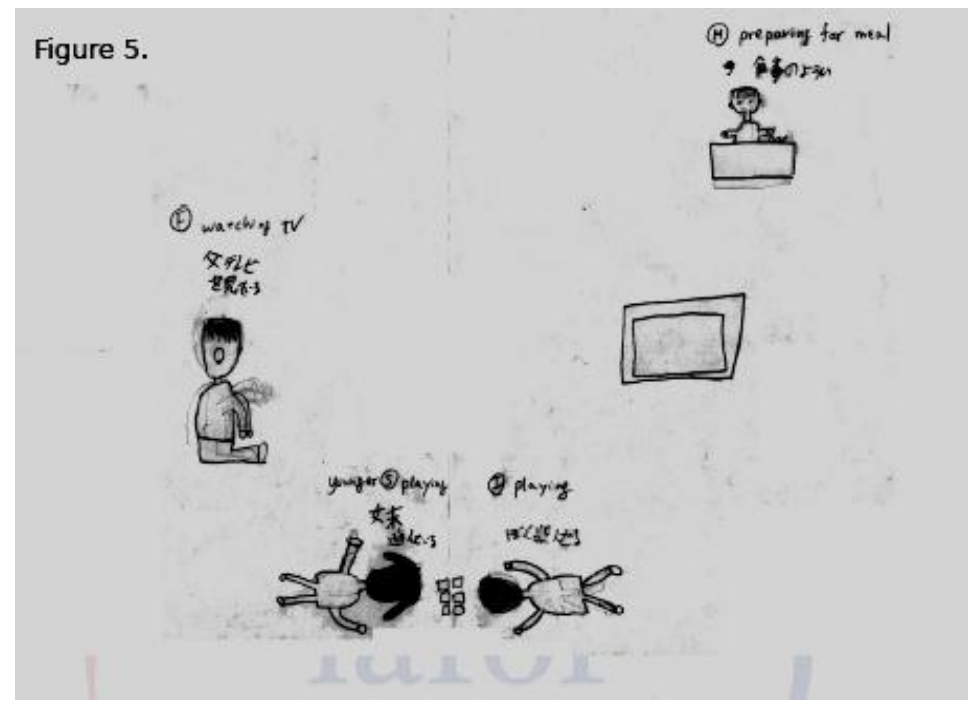

FIGURE 5

As shown in Figure 5. This figure shows a boy who has an average attitude in daily life and a reliant attitude in studying circumstances. He has shown an aggressive inner feeling toward parents through depicting a childish image of the parents that shows helplessness; refusal of the family situation (drawing back facing); no family communication and parental deprivation, especially the mother who seems to be more dominant than the father (long distance between him and the 
drawn figure of the mother on the top of the paper), dependent tendency (tiny foots), Maybe there is a way of communication with sister but in a refusing reaction to the family. There is also an ambivalent feeling toward all the family members, which is indicated through erasing the drawings. An inadequacy feeling has been shown through drawing tiny persons and indication of no motor action may indicate such depressive sign.

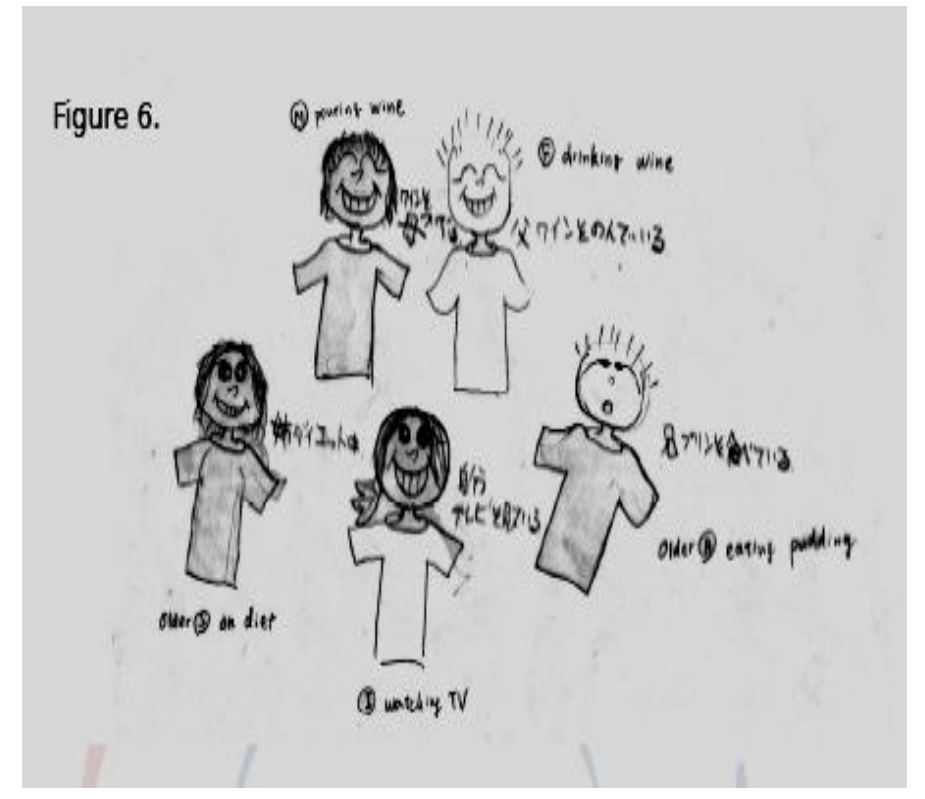

FIGURE 6

As shown in Figure 6. This figure shows a girl who has an average attitude in daily life and an independent attitude in studying circumstances scenes toward her parents. She has shown an indication of aggressive inner feelings toward parent (distorted body image, as if cartoon characters; emotional conflict; no family communication and psychological castration (omission of legs, arms, hands; prominent teeth), lose of independency (omission of foots), Parental closed eyes may indicate lack of parental care; and no motor action has been seen. 


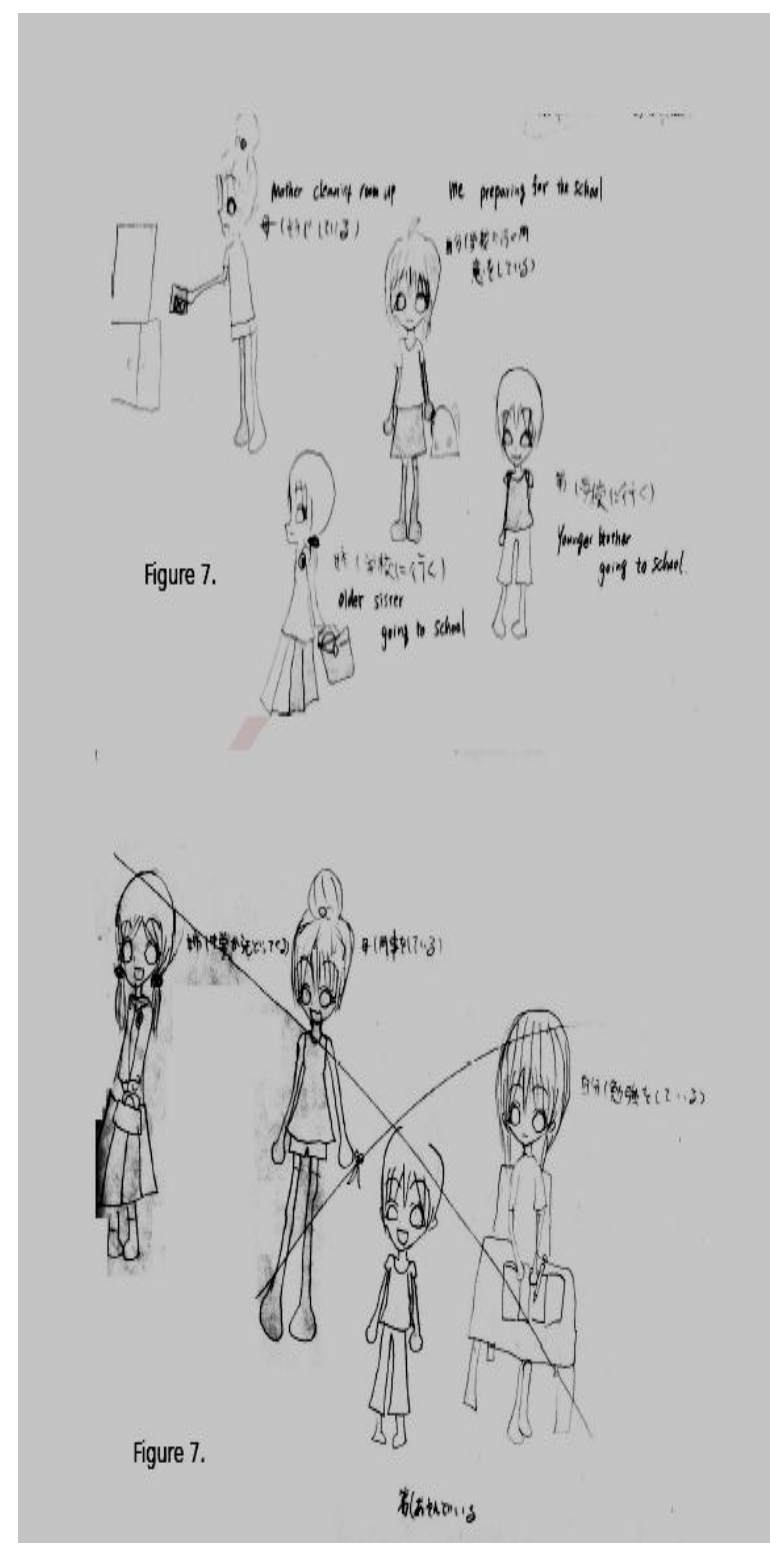

FIGURE 7

As shown in Figure 7. This figure shows a girl who has an independent attitude in daily life and an estrangement attitude in studying circumstances toward parents. She has shown an inner feeling of aggression toward the family (closing hands, omitting the apple eye, drawing an " $X$ sign" on the family on the back of the paper); maternal deprivation (mother is busy cleaning); aggressive feeling toward her younger brother (mother holding scissors toward her brother on the drawing back); mother may be a threatening figure. Drawing a closing mouth after opening mouth on the back of the paper indicates denial of verbal aggression; father's absence and lack of family communication can be seen through omitting the apple of the eye and closing mouse. 


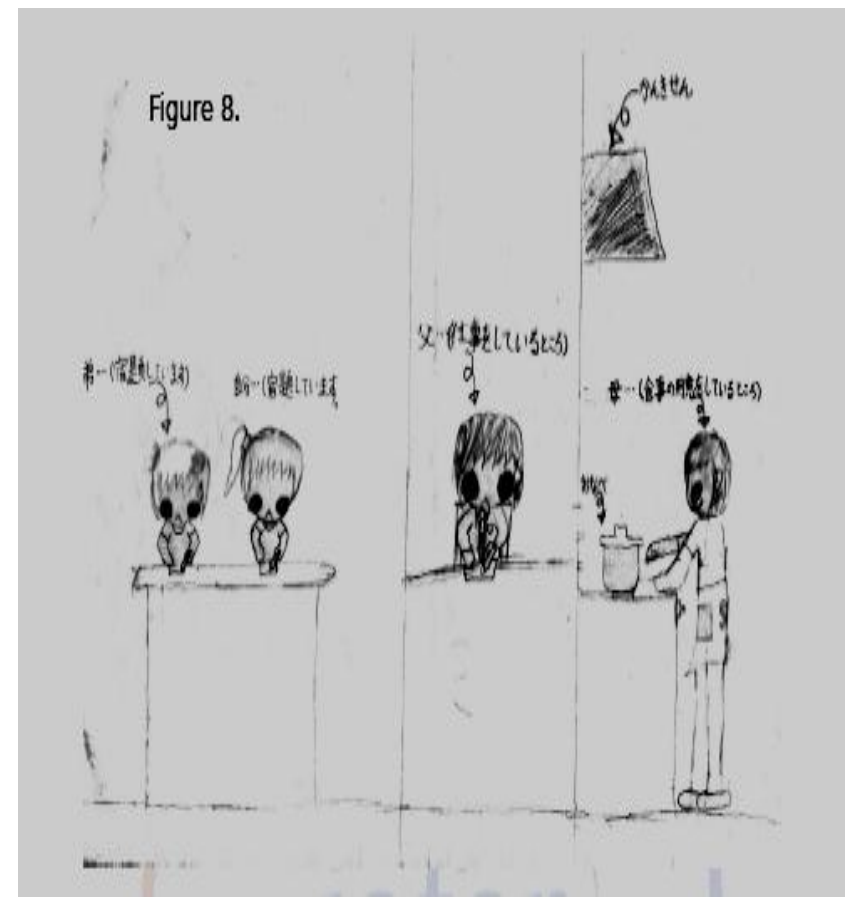

FIGURE 8

As shown in Figure 8. A girl has not answered the $\mathrm{FMCl}$; she has shown a maternal deprivation (drawing compartments and long distance between mother and her); love need (mother cooking food); and oral deprivation; identification with father (studying like him). An indication of scanning the world for information can be seen through drawing large eyes; however, drawing a small and closed mouth may indicate such a denial mechanism of verbal aggression. 


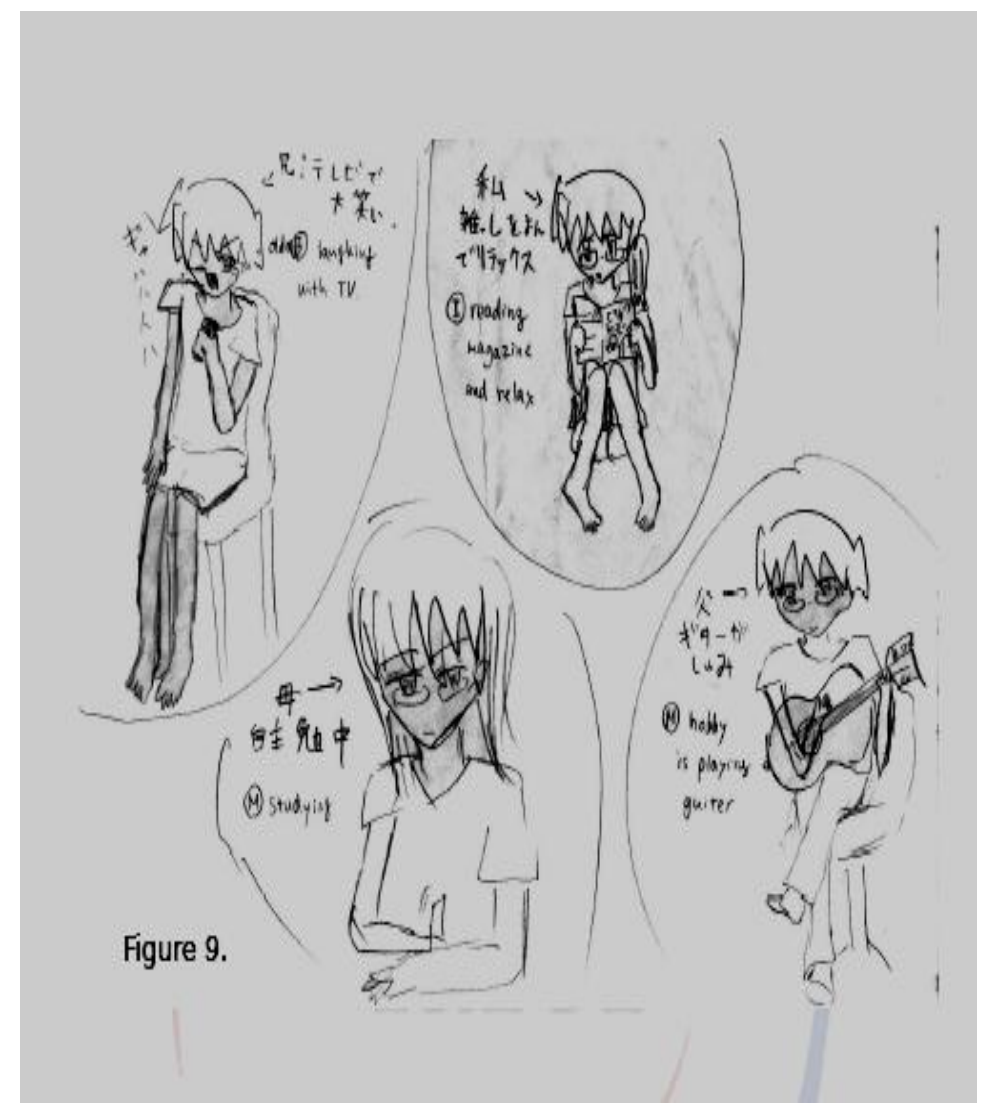

FIGURE 9

As shown in Figure 9. This figure shows a girl who has a pampered attitude in daily life scenes and an average attitude in the studying circumstances scenes toward her parents. She has shown such a denial mechanism of verbal aggression "closed mouth of all figures"; however, feelings of sadness and lack of warm family communication has obviously been shown through drawing "folded compartmentalization, facial features". 


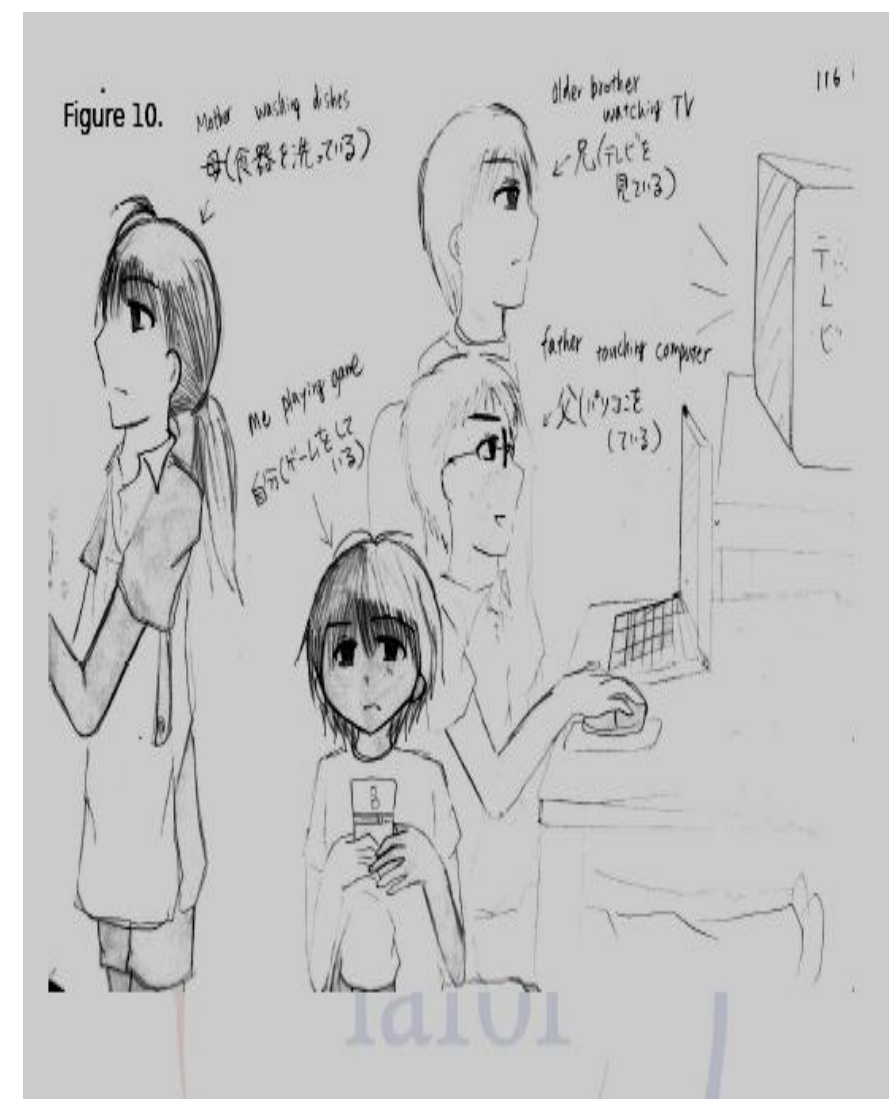

FIGURE 10

As shown in Figure 10. This figure shows a girl who has a dependent/childish attitude toward parents in daily life scenes and studying circumstances scenes. She has shown verbal aggression (closed mouth) and aggression toward mother (cutting her hands through the paper side) since the mother was very busy (washing dishes) and gave back face to the family, which is an indication of such maternal deprivation. Normal family communications, especially with father, and feelings of sadness have obviously been seen.

\section{K.F.D}

KFD, reveals the family dynamics and the complex family system as affirmed by Schwartz, (1981) and Bowers, (2002) According to the projective drawing tests perspectives (Kaufman, 1972; Anderson and Anderson, 1951), dynamic analysis correlated with $\mathrm{FMCl}$ results has shown the following:

2.1 Feelings of aggression have shown through: 
2.1.A Denial of the human body image (parents, self) as if it was machine, cartoon and image of body distortion.

2.1.B Refusing family relations (missing eyes, ears, hands, etc; giving back facing to parents; closing eyes and drawing compartments). They all have been shown as follows:

2.1.B.1. Eleven students have shown a strong indication of aggressive inner feelings toward parents and distorted human body image; those students were as follows:

a. Six students have a dependent attitude toward parents;

b. Three students have an independent or rebellious attitude toward parents;

c. One student has a dependent attitude in daily life scenes and a rebellious attitude in studying circumstances scenes;

d. One student has an estrangement attitude toward parents.

2.1.B.2 One student has shown aggression toward parents (distorted parental body image); this case has a pampered attitude toward parents in daily life scenes and an independent attitude in studying circumstances scenes.

2.1.B.3 Fourteen students have shown less indication of aggressive inner feelings and distorted body image (through drawing distorted hands or legs); however, repressed aggression has shown through drawing closing hands; those students were as follows:

a. Seven students had a dependent-reliance and childish attitude toward parents;

b. One student has shown an estrangement and pampered attitude;

c. Two students have an independent-rebellious attitude;

d. One student has shown an estrangement attitude;

e. One student has shown both attitudes (reliance and rebellious) that may indicate a confused attitude toward parents;

f. One student has shown a rebellious attitude;

g. One student did not answer the $\mathrm{FMCl}$ questionnaire.

2.1.B.4 Four students have not shown aggressive inner feelings or a distorted body image; however, no family communication has been shown:

a. Three students have shown a dependent, pampered, childish or reliance attitude toward parents;

b. One student has shown an independent attitude. 
2.2 Psychological castration has obviously been seen through omission of hands or legs;

2.3 No psychological and normal warm family communications have been observed (Omission of eyes, ears; giving back facing to parents; closing eyes and drawing compartments).

2.4 Lose of independency or dependent tendency have been shown (draw tiny foots or omit it).

\section{Discussion}

"A baby alone does not exist" (Winnicott, 1965, p.91). "Mother, Parents, Family, Groups, Community, Society and Culture have a strong impact on the individual's personality." Despite arguments, all theoretical perspectives almost agree with the important influence of the interpersonal relations in contact with the system (mother, family, group) on the personality. Psychodynamic perspectives appreciate the power of the unconscious and the way early childhood shapes the person's current psychological state (Gabbard, Glen 2005); The humanistic perspective believes that the individual has inbuilt potentials that might help him to build a strong personality through unconditional positive regard and empathetic understanding (Schneider et al, 2001); The behavioral and cognitive behavioral perspective, which has been rooted in behaviorism, where environmental events predict the way we think and feel (Beck et al, 2007); social learning theory appreciate the impact of experiences, observations, and modeling to learn or imitate behaviors (Henry $P$ sims Jr. and Charles C Man Z. (1982); and a reciprocal determinism, bilateral influences among the individual and the environment (Bandura, 1977); The family system perspective emphasizes family relationships, focusing on the socio-cultural context as it forms the family system and all kinds of interpersonal relationships. Thus, socio-cultural and family systems, interpersonal aspects, attachment and object relations theories and social learning theory are included in order to understand the children's feelings toward parents.

The parent-child relationship is embedded in and influenced by external relationships, which in turn are embedded within larger socio-cultural historical systems (Hinde and Stevenson, Hinde, 1987). Moreover, the external and internal aspects (behavioral, representational) of relationships and represents of emotions are influenced by culture (Planalp and Fitness, 1999). The family system theory includes mutual influences between individuals with a relationship and mutual influences among relationships, Hinde, (as cited in Kreppner, and lerner, 1989). 
Thus, behaviors of both parent and child are linked, one giving rise to the other in cycles of reciprocal causality (Lollis and Kuczynski, 1997). Children and parents' views of their relationships arise in part from their individual experiences and in part from the history of their relationships, Kent and Pepler, (as cited in Kuczynski, 2003). In this way, a stable system of mutually coercive cycles of interaction is established through the countless daily interactions of early childhood (Patterson, 1982; Reid and Patterson, 1989). Through coercive family processes, children learn how to utilize aversive responses to terminate the aversive behaviors of parents and siblings, Kent and Pepler (as cited in Kuczynski, 2003). Since it is best to understand childhood development as embedded in a variety of social and other ecological contacts, including community and cultural contexts that impact the family processes of child development (Bronfenbrenner, 1979), The Japanese inherited system of dependency in early childhood through the family and group may be characterized the children (Doi, 1981, 2008).

Referring to Harry Stack Sullivan, (interpersonal psychoanalysis), "Personifications embody one's assumptions, schemata, internalized representations of others and reflected appraisals of the self." They can form the basis for the later ambiguities in interpersonal relations that Sullivan termed "Parataxic distortion," a very similar concept to the standard psychoanalytic Transference Projection mechanisms (Brinich \& Shelley, 2002, P. 65). Sullivan saw human personality as being formed of interpersonal relations. According to Bowlby (1973, 1980), attachment theory, experience with primary caregivers, leads to generalizing expectations and beliefs (working models) about self, the world and relationships; $\mathrm{He}$ describes these representations as persistent and yet open to revision in light of experience. The early relationship acts as an external system for the child's internal regulation.

As for the object relation's theory, object relationships are formed during early interactions with caregivers and then the infants' images of people and events turn into objects in the subconscious, which he/she carries into adulthood. Objects, internalized images of one's parents can also be parts of a person. Objects can reshape later experiences; yet still continue to be a strong influence in one's life (St. Clair, Michael, 2000).

By the middle childhood (ages 7-11) there may be a shit toward mutual coregulation of secure - base contact in which caregiver and child negotiate methods of maintaining communication and supervision as the child moves toward a 
greater degree of independence (waters E etal, 1991), The studies of Bobo doll experiments of Bandura and colleagues published revealed that, children whom exposed to the aggressive model were more likely to imitate what they had seen and behave aggressively toward the doll. (Bandura, A and Ross, D, 1961). The current study shows that children suffer from a double hurt A dependent tendencies that have rooted by the Japanese culture through Ame's mentality, the unique interpersonal relationships, attachment and family system that reinforced by experiences, observations, or models in the society which is consistent with the study of sroufe and eta,al (1983) that the quality of infant - Caregiver attachment influences later dependency and, Bienenfeld (2008) and the psychodynamic causes of an insecure form of attachment to others; at the same time, lack of warm family relations. Such situation raises aggression toward the inner objects (parents) and self, as they are parts of the self.

\section{Conclusion:}

The study aims to identify the attitudes of the Japanese parent-child relationship and the child's inner feelings toward his/her parent. The children have responded to the father mother and child relationship inventory (FMCl); and the kinetic family drawing test. Referring to the unique status of the Japanese culture, and the influence of Amae's mentality; and with regard to the questions of the study, the results have concluded that:

1-The common perceived parental attitude toward children in both daily life and studying circumstances scenes was almost acceptance; no significant gender difference has been observed $(67.7 \%$ of the girls and $60.7 \%$ of the boys).

2-The children common attitude toward their parents was dependency in both daily life scenes $(38.7 \%$ of the girls and $35.7 \%$ of the boys), and studying circumstances scenes ( $645 \%$ of the girls and $53.5 \%$ of the boys); no significant gender difference has been observed.

3-No significant gender differences have been observed regarding to subscales / attitudes except:

1- A significant average perceived parental attitude has been reported among girls $(12.9 \%$ of the girls and zero of the boys) in the daily life scenes

2- A significant idealistic perceived parental attitude has been reported among girls ( $42 \%$ of the girls and $17.9 \%$ of the boys) in the studying circumstances scenes.

4-Most of the drawings have shown aggressive inner feelings toward parents, parental emotional deprivation and no warm family relations, as well as feelings of 
sadness, inadequacy, dependent tendency (which, may validate the results of the $\mathrm{FMCl}$ inventory), and psychological castration; that may be consistent with the study of bousha et.al (1984) that maltreated children shawes fewer positive behaviors and aggressive behaviors; Makoto (2009) and the rejected and negative mothers influence child dependency; Hakvoort (2010); Akca (2011) the abnormal parent child relationship and the child developmental and psychological problems; and Page et.al (2011) the maternal uncertainty and the child depressive symptoms. In this way, children who have shown a resistance or a rebellious attitude toward parents are normal and they react in a healthy way in such situations.

Finally, it is necessary to mention with Erikson (1963, P. 405) that "society must prepare early for parenthood in its childhood and it must take care of the unavailable remnants of infancy in its adulthood".

\section{Recommendation}

Further researches and larger samples are recommended to emphasis the results

\section{References}

- Ainsworth, M. (1969). Object Relations, Dependency, and Attachment: A Theoretical Review of the Infant-Mother Relationship. Child Development, 40, 969-1025

- Akca, OF Ugur, C., Colak, M., Kartal, OO Akozel, AS Erdogan, G., and Uslu, RI. (2011). Under involved Relationship Disorder and related factors in a sample of young children. Early Human Development. [Epub ahead of print]

- Anderson, H.H., and Anderson, G.L. (1951). An Introduction to Projective Techniques and Other Devices For Understanding the Dynamics of Human Behavior. Prentice- Hall, Inc. Englewood Cliffs, N.J.

- Anderson, L. (2004) A comparison of kinetic family drawings of firstborn and second-born siblings. Andrews University, AAT 3122211

- Bandura, A. (1971) "Psycholgical Modelling". New York: Lieber - Antherton.

- Bandura, Albert. (1977)- Social learning theory. Oxford, England: Prentice Hall.

- Bandura, A; Ross, D.; Ross, S.A. (1961). Transmission of aggression through the imitation of aggressive model's. journal of abnormal social psychology 63 (3): 575-582. 
- Beck, A., Davis, D., and Freeman, A. (2007). Cognitive Therapy of Personality Disorders, $\left(2^{\text {nd }}\right.$ Ed). New York: Guilford Press.

- Behrens, Kazuko .Y. (2004) Multifaceted View of the Concept of Amae: Reconsidering the Indigenous Japanese Concept of relatedness. Human Development; 47 (1); $1-26$

- Bienenfeld, David. (2008) "eMedicine-Personality Disorders"

- Bousha,, David. M.; and Twentyman, Craig .T. (1984). Mother - Child interaction style in abuse, Neglect, and Control Groups: Nationalistic Observations in home. Journal of Abnormal Psychology, 93 (1), 106-114.

- Bowers, B. S. (2002) A cross-cultural study of family drawings by American, Korean, Japanese, and Chinese university students: Testing cultural constructs. The Ohio State University, AAT 3059206

- Bowlby, J. (1973). Separation: Anxiety \& Anger. Attachment and Loss (2); (International psycho-analytical library no.95). London: Hogarth Press.

- Bowlby, J. (1980). Loss: Sadness \& Depression. Attachment and Loss (3); (International psycho-analytical library no.109). London: Hogarth Press.

- Branje, Hale. Frijns., and Meeus. (2010). Longitudinal Associations Between Perceived Parent-Child Relationship Quality and Depressive Symptoms in Adolescence. J. Abnormal Child Psychology, 38:751-763, DOI 10.1007/s10802-010-9401-6.

- Brinich, P., and Shelley, C. 2002. The Self and Personality Structure. Buckingham: Open University Press.

- Bronfenbrenner, U. (1979). The Ecology of Human Development: Experiments by Nature and Design. Cambridge, MA: Harvard University Press.

- Bugola, J. A. (1995) Daughters' perceptions of father-daughter relationships and their associations with eating disorders. Northern Arizona University, available on www.proquest.com

- Burn, R., and Kaufman, H. (1972) Actions, styles and symbols in kinetic family drawings (K.F.D) an interpretative manual, published by BrunnerRoutledge, New York.

- Carolus, M. J. L. Vereijken et al. (1997). Mother - Infant Relationship in Japan" Journal of Cross-Cultural Psychology. 28(4), 442-462. 
- Chamberlain, C. C. (2002) Object relations' theory and family dynamics in schizophrenic patients, non-psychotic patients, and controls: An empirical study. By Ph.D., University of Detroit Mercy.

- Comer, R.J. (2010) Abnormal Psychology, seventh Edition. New york, NY: Worth publishers.

- Diagnostic and statistical Manual of Mental Disorders, $4^{\text {th }}$ (DSM-IV) Edition, Text Revision.

- Doi, T. (1973). The Anatomy of Dependence, John Bester, trans. Tokyo: Kodansha International.

- Doi, T. (1977). The anatomy of dependence. Translated by John Bester: Kodansha International Ltd., Tokyo, New York and San Francesco.

- Doi, T. (2008) the anatomy of dependence, translated by John Bester, Kodansha International, Tokyo, New York and London.

- Doi, Takeo. (1981). The Anatomy of Dependency: The key Analysis of Japanese Behavior, Translated by John Bester, Kodansha International, Tokyo, $2^{\text {nd }}$.

- Erikson, Erik. H. (1963) Childhood and Society, 2nd Edition, Revised and Enlarged. W. W. Norton Company Inc. New York,

- Fraser, M. (1996) Aggressive behavior in childhood and early adolescence: An ecological-developmental perspective on youth violence. Social Work (41) 4, 347-61

- Gabbard, Glen. (2005). Psychodynamic Psychiatry in Clinical Practice, 4th ed. Washington, DC: American Psychiatric Press.

- Garton, A. F. (2007). Learning through Collabroation: Is there a multicultural perspective? AIP. pp. 195-216.

- Gray, LB Weller, RA Fristad, M., and Weller, EB. (2011). Depression in children and adolescents two months after the death of a parent. J. Affective Disorders. 135 (1-3): 277-83.

- Grusec, Joan (1992). "Social Learning theory and developmental Psychology: The legacies of Robert Sears and Abert Bandura". Developmental Psychology 28 (5).

- Hakvoort E. M., Bos H. M. W., Van Balen, F., Hermanns., and Jo, M. A. (2010) Family Relationships and the Psychosocial Adjustment of SchoolAged Children in Intact Families. The Journal of Genetic Psychology, 171(2), 182-201. 
- Harold, Homer. Anderson Gladys, M., (Lowe), Jt., and Ed, Anderson. (1964). An Introduction to Projective Techniques and Other Devices, for Understanding the Dynamics of Human Behavior. Edited by Harold $\mathrm{H}$. Anderson and Gladys L. Anderson. Prentice-Hall Psychology Series.

- Henry P sims Jr. \& Charles c Man z. (1982). Social Learning theory, Journal of organizational behavior Management, 3: 4, 55-63.

- Herman, W. Smith \& Takako, Nomi. (2000). "Is Amea the Key to understanding Japanese Culture?"Electronic Journal of Sociology.

- Hinde, R. A. (1989). Reconciling the Family Systems and the Relationships Approaches to Child Development. In Kreppner, Kurt \& Lerner Richard M. (Eds.), Family systems and life-span development, (149-164). London: Lawrence Erlbaum Associates

- Hinde, R., And Stevenson, Hinde. (1987). Interpersonal relationships and child development. Developmental Review, 7, 1-21.

- Hiroyuki, Tahara., Minoru, Okita., Toshiya, Tsurusaki., Shigeru, Inokuchi., and Toshio, Higashi. (1997). Validity and Reliability of the Japanese Version of the Self Esteem Inventory. Journal of Physical Therapy Science, 9: 8792.

- Kerns KA. (2008) "Attachment in Middle Childhood". In Cassidy J, Shaver PR. Handbook of Attachment: Theory, Research and clinical Application. New York and London: Guilford Press. PP. 366-82. ISBN 978-1-59385874-2.

- Kotaro, H. (1998). Father Mother and Child relationship Inventory", App/90, Toshobunkasha, Japan.

- Krapp, K. M., Wilson, J., and Cengage, G. (2005). The Gale Encyclopedia of Children's Health. Infancy Through Adolescence (2nd ed.,). Cengage Gale Publisher.

- Kuczynski, Leon. (2003). Handbook of Dynamics in Parent-child Relations. Sage Publications, Inc

- Lieberman, F. R. (1992). Validity of the Kinetic Family Drawings as a measurement of the perception of family relationships and family dynamics. Ph.D., Pace University, AAT 9225986

- Lieberman, M., Doyle, AB Markiewicz, D. (1999). Developmental patterns in security of attachment to mother and father in late childhood and early 
adolescence: associations with peer relations. Child Development. 70 (1): 202-13.

- Lollis, S., \& Kuczynski, L. (1997). Beyond one hand clapping: Seeing bidirectional in parent-child relations. Journal of Social and Personal Relationships, 14, 441-461.

- Lucas,Thompson. RG Goldberg, WA. (2011). Family relationships and children's stress responses. Advances in Child Development and Behavior. 40, 243-99.

- Maccoby, E., \& Masters, J. Attachment and Dependency. IN P.H. Mussen (Ed.), (1970) Carmichael's manual of child psychology. (2), 74-75. New York: Wiley.

- Makoto, Tsumori et al, (2009)."Development of a child's personality and the parent-child relationship [in Japan]. The Japanese Association of Educational Psychology, 9 (3): 129-145, 186-187,

- Malmberg, LE and Flouri, E. (2011). The comparison and interdependence of maternal and paternal influences on young children's behavior and resilience. J Clinical Child and Adolescence Psychology. 40(3): 434-44.

- Marchiori, E., Loschi, S., Marconi, PL Mioni, D., and Pavan, L.( 1999 ) Dependence, locus of control, parental bonding, and personality disorders: a study in alcoholics and controls. Alcohol and Alcoholism. 34(3):396-401.

- McDonald, K L., Bowker, J. C., Rubin, K. H., Laursen, B., and Duchene, M. S., (2010). Interactions Between Rejection Sensitivity and Supportive Relationships in the Prediction of Adolescents' Internalizing Difficulties. J Youth Adolescence, 39:563-574. DOI 10.1007/s10964-010-9519-4.

- Monahan, M. V. (1985). Situational Influences On Children's Kinetic Family Drawings. PhD Indiana University, AAT 8602412

- Mongrain, M. (1998). Parental representations and support-seeking behaviors related to dependency and self-criticism. J. Personality. 66(2):151-73.

- Page, MC., Fedele, DA., Pai, AL., Anderson, J., Wolfe,Christensen. C., Ryan, JL., and Mullins, LL. (2011). The Relationship of Maternal and Child Illness Uncertainty to Child Depressive Symptom otology: A Meditational Model. J Pediatric Psychology. 19. [Epub ahead of print]

- Patterson, G. R. (1982). Coercive family process. Eugene, OR: Castalia. 
- Planalp, S., \& Fitness, J. (1999). Thinking/Feeling about social and personal relationships. Journal of Social and Personal Relationships, 16, 731-751.

- Raudino, A., Woodward, L.J Fergusson, DM.,and, Horwood, LJ. (2011). Childhood Conduct Problems Are Associated with Increased Partnership and Parenting Difficulties in Adulthood. J Abnormal Child Psychology. 9. [Epub ahead of print]

- Raya, A. F., Pino, M. J., and Herruzo, J. (2011). Family variables related to behavioral problems in childhood. Isr. J. Psychiatry and Related Science 48 - (2) 117- 122.

- Reid, J. B., \& Patterson, G. R. (1989). The development of antisocial behavior patterns in childhood and adolescence. European Journal of Personality, 3, 107-119.

- Richaud, de Minzi, M. C. (2006). Loneliness and Depression in Middle and Late Childhood: The Relationship to Attachment and parental styles. The Journal of Genetic Psychology; 167 (2); 189- 210.

- Rosenfarb, IS., Becker, J., Khan, A., and Mintz, J. (1994). Dependency, selfcriticism, and perceptions of socialization experiences. J Abnormal Psychology, 103(4): 669-75.

- Rothbaum, F., Kakinuma, M., et al, (2007). Attachment and Amae: Parent child closeness in the United States and Japan" Journal of Cross-Cultural Psychology, 38, 465-486.

- Schneider, Bugental, J., and Pierson, J. (2001). The handbook of humanistic Psychology: Leading Edges in Theory, Research and Practice, 2nd ed. Thousand Oaks, CA: Sage Publications

- Schwartz, E. E., (1981). The Kinetic Family Drawing As A Family Assessment Measure. Ph.D., Boston College.

- Scott,S., Briskman, J., Woolgar, M., Humayun, S.,and, O'Connor, TG.(2011). Attachment in adolescence: overlap with parenting and unique prediction of behavioral adjustment. Child Psychology \& Psychiatry. 52(10), 1052-62. doi: 10.1111/j.1469-7610.2011.02453.x.

- Shwalb, David. W. Shwalb, Barbara. J. (1996)." The Japanese childrearing" foreword by Takeo Doi, The Guilford Press. Culture and Human Deployment Sara Harkness and Charles M. Super Series Editors, p. 114-168. 
- $\quad$ Sroufe, L., Alan, Fox. E., Nancy and Pancake, R. Van. (1983). Attachment and Dependency in Developmental perspective. Child Development, 54(6), 161527.

- St, Clair. Michael. (2000). (Trade paperback). Object Relations and SelfPsychology: An Introduction (3rd ed.). Brooks/Cole Counseling, an imprint of Wadsworth, a division of Thomson Learning. p. 6.

- Stawar, T. L., Stawar, D. E., (1989). Kinetic Family Drawings and MMPI diagnostic indicators in adolescent psychiatric inpatients. Psychological Reports. 65 (1), 143 .

- Vaughn, B. E., El-Sheikh, M., Shin, N., Elmore, Staton. L., Krzysik, L., and, Monteiro, L. (2011). Attachment representations, sleep quality and adaptive functioning in preschool age children. Attachment and Human Development. 13(6), 525-40.

- Waller, EM., and, Rose, AJ., (2010). Adjustment trade-offs of co-rumination in mother-adolescent relationships. J Adolescence. 33(3), 487-97.

- Waters E, kondo- Ikemura K, Posada G, Richters J. (1991). "Learning to love: Mechanisms and milestones". In Gunnar M, Sroufe T. Minnesota symposia on child psychology 23 (self - processes and development). Hillsdale, $\mathrm{Nj}$ : Erlbaum.

- Weinfield NS, Sroufe LA, Egeland B, Carlson E. (2008). "Individual Differences in infant - Caregiver Attachment". In Cassidy J, Shaver PR. Handbook of Attachment: Theory, Research and clinical Applications. New York and London: Guilford Press. PP. 78-101 ISBN 978-1-59385-874-2.

- Williams, S., Conger, K., and Blozis, S. (2007). The Development of Interpersonal Aggression During Adolescence: The Importance of Parents, Siblings, and Family Economics. Child Development 78. (5), 1526-1542.

- Winnicott, D. (1965). family and individual development. London: Tavistock.

- Wolfe, D.A \& Mclsaac, C. (2011). Distinguishing between poor/dysfunctional parenting and child emotional maltreatment. Child Abuse and Neglect. 35(10), 80213.

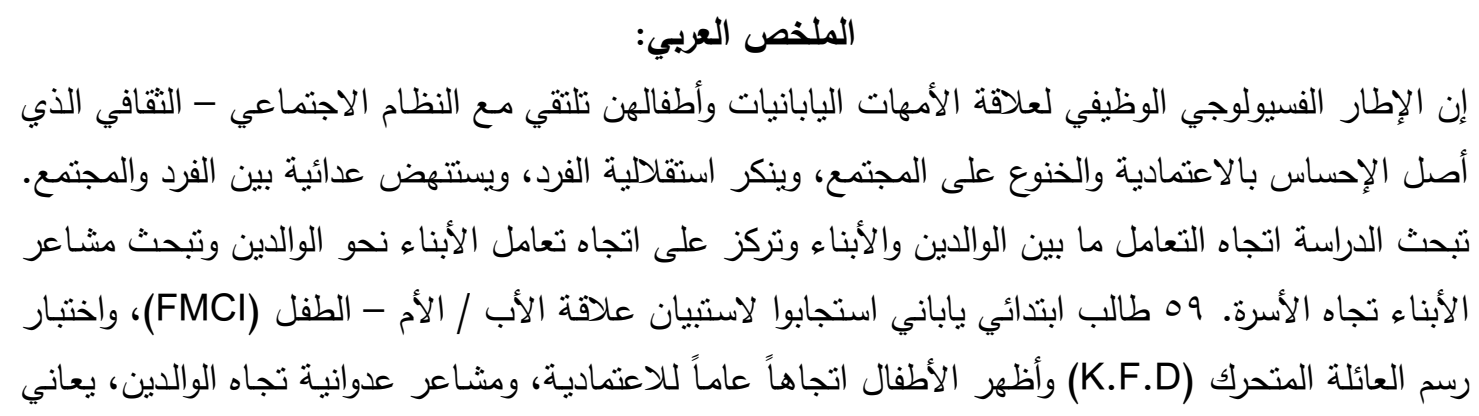


الأطفال من انجراح مزدوج، استعداداً للاعتمادية ونقص في العلاقات الأسرية الدافئة ولذلك، فهؤلاء الأطفال الذين أظهروا اتجاهات غريبة ورفض تجاه الوالدين تعتبر ردود أفعال طبيعية. 